This item was submitted to Loughborough's Research Repository by the author.

Items in Figshare are protected by copyright, with all rights reserved, unless otherwise indicated.

\title{
A study on LQG/LTR control for damping inter-area oscillations in power systems
}

PLEASE CITE THE PUBLISHED VERSION

PUBLISHER

(c) IEEE

VERSION

VoR (Version of Record)

LICENCE

CC BY-NC-ND 4.0

\section{REPOSITORY RECORD}

Zolotas, Argyrios C., B. Chaudhuri, I.M. Jaimoukha, and Petr Korba. 2019. "A Study on LQG/LTR Control for Damping Inter-area Oscillations in Power Systems". figshare. https://hdl.handle.net/2134/4313. 
This item was submitted to Loughborough's Institutional Repository (https://dspace.lboro.ac.uk/) by the author and is made available under the following Creative Commons Licence conditions.

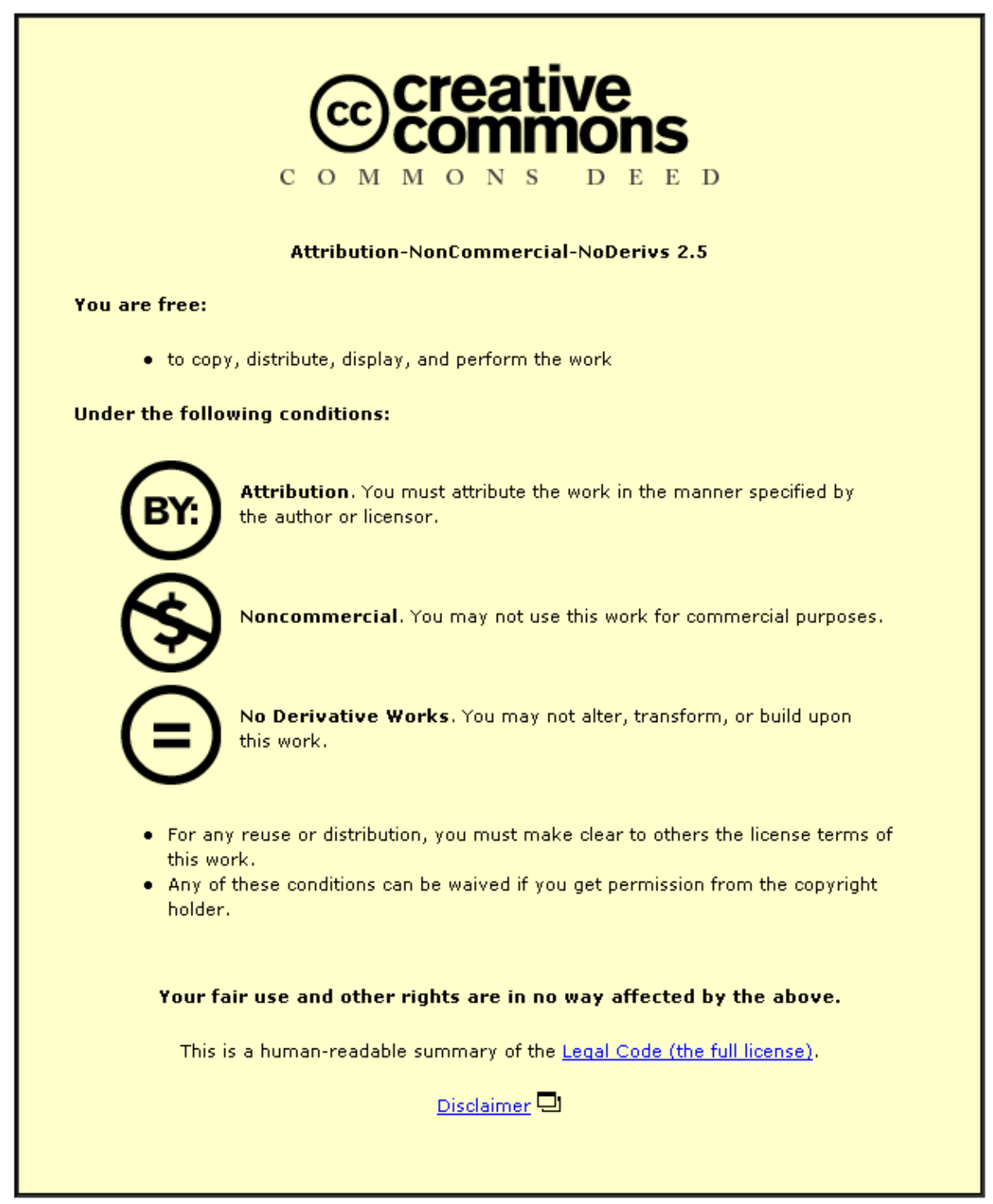

For the full text of this licence, please go to: http://creativecommons.org/licenses/by-nc-nd/2.5/ 


\title{
Brief Papers
}

\section{A Study on LQG/LTR Control for Damping Inter-Area Oscillations in Power Systems}

\author{
Argyrios C. Zolotas, Member, IEEE, Balarko Chaudhuri, Student Member, IEEE, Imad M. Jaimoukha, and \\ Petr Korba
}

\begin{abstract}
This brief presents results on a robust linear quadratic Gaussian (LQG) damping control scheme for improving the inter-area mode oscillations of power systems. A technique is also proposed to guarantee minimum-phase/well-damped transmission zeros by appropriately "squaring" the design plant, for the purposes of efficient robust recovery. A 7th-order multiple-input single-output (MISO) centralized controller is designed for a 16-machine, 5-area power system (138th order) reinforced with a thyristor-controlled series capacitor (TCSC) to improve the damping of the critical inter-area modes by employing appropriate global signal measurements. Loop transfer recovery (LTR) is then applied to reinforce controller robustness in the case of faults and unknown disturbances. The performance of the designed system is assessed in the frequency domain and via appropriate time-domain simulations based upon the nonlinear model under a variety of scenaria.
\end{abstract}

Index Terms-Flexible ac transmission systems (FACTS) devices, inter-area oscillations, linear-quadratic Gaussian, loop transfer recovery, power systems, reduced order systems, robust control, transmission zeros.

\section{INTRODUCTION}

D AMPING inter-area oscillations is one of the major concerns for the electric power system operators [1]. With ever increasing power exchange between utilities over the existing transmission network, the problem has become even more challenging. Secure operation of power systems, thus, requires the application of robust controllers to damp these inter-area oscillations [2]. Power system stabilizers (PSSs) are the most commonly used devices for this purpose [3], [4]. Nowadays, flexible ac transmission systems (FACTS) devices [5] are receiving growing attention as alternatives to transmission system reinforcement which is otherwise restricted due to economic and environmental considerations. Besides,

Manuscript received July 7, 2004; revised October 31, 2005. Manuscript received in final form June 14, 2006. Recommended by Associate Editor A. Bazanella. This work was supported in part by Asea Brown Boveri (USA) and by the Engineering and Physical Sciences Research Council (U.K.) under Grant GR/R/31676.

A. C. Zolotas was with the Department of Electrical and Electronic Engineering, Imperial College, London, SW7 2BT, U.K. He is now with the Department of Electronic and Electrical Engineering, Loughborough University, Loughborough, LE11 3TU, U.K. (e-mail: a.zolotas@ieee.org).

B. Chaudhuri and I. M. Jaimoukha are with the Department of Electrical and Electronic Engineering, Imperial College, London, SW7 2BT, U.K. (e-mail: b.chaudhuri@imperial.ac.uk; i.jaimouka@imperial.ac.uk).

P. Korba is with the ABB Switzerland Ltd., Corporate Research, Baden-Dättwil CH-5405, Switzerland (e-mail: petr.korba@ch.abb.com).

Digital Object Identifier 10.1109/TCST.2006.883232 power flow and voltage control, supplementary control is being incorporated to these FACTS devices to damp inter-area oscillations at relatively small additional cost. The objective of the control design exercise is to ensure adequate damping under credible operating conditions utilizing a thyristor controlled series capacitor (TCSC).

The task of control design is challenging, owing to the complex nature of the interactions in the inter-area modes of the system. $\mathcal{H}_{\infty}$ methods received increased attention in power systems [6]-[10], however, issues with weighting function selection make the whole design procedure difficult. Linear quadratic Gaussian (LQG) control approaches using different FACTS devices have been presented for closed-loop identification in [11], [12], and power system stabilizer (PSS) for small systems in [13]. Recently, [14] presented work on a power system network with a TCSC device which partially relates to this brief, however, it is only applied to a rather small single-input, singleoutput (SISO) system and addresses the loop transfer recovery (LTR) problem from a simulation point of view.

The contribution of this work is the utilization of LQG/LTR control in a rigorous manner via a proposed minimum-phase square system augmentation to guarantee a return ratio for achieving appropriate robustness properties. The study system focuses on a 16-machine 5-area power network controlled by a centralized TCSC device using three global (remote) measurements. Extensive emphasis on model reduction simplifies the structure of the 138th-order equivalent model representation of a large power network for straightforward model-based control design, while the system performance objective is tackled via the LQR minimization index. The effectiveness of the proposed technique is verified via both frequency domain assessment and nonlinear time domain simulations for a variety of operational scenaria. The study illustrates the fact that multiple swing modes can be damped through a single actuator (FACTS) using appropriate control design methodology in the multivariable framework.

\section{System Modeling AND Design ReQuiRements}

\section{A. Study System}

The damping control design under study consists of a 16-machine 5-area power system and is depicted in Fig. 1. The diagram represents an approximate model of the New England (NETS) and New York (NYPS) interconnected network. More details on the system description and its characteristics including machine, excitation system, and network parameters can be found in [8]. 


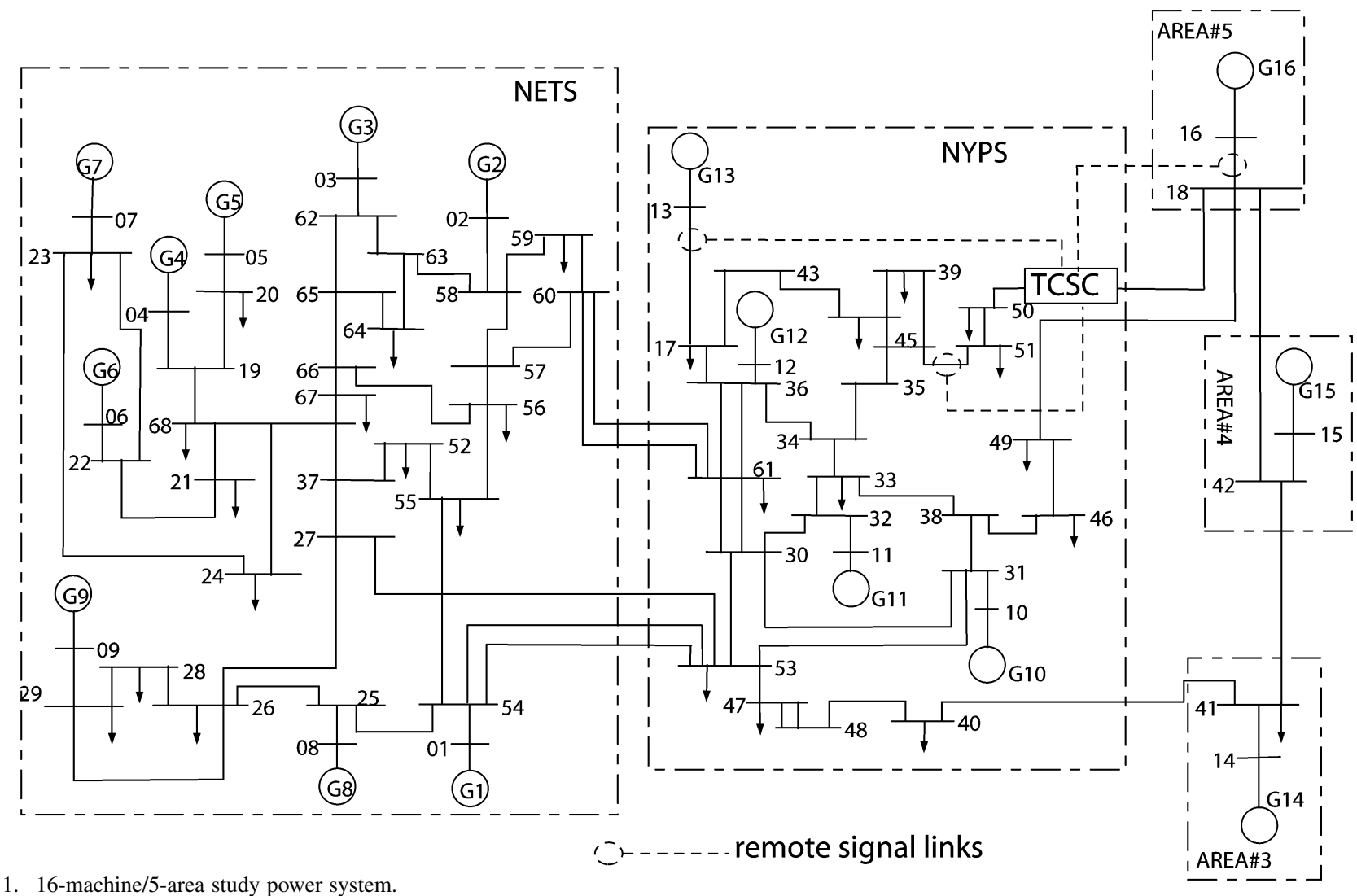

Fig. 1. 16-machine/5-area study power system.

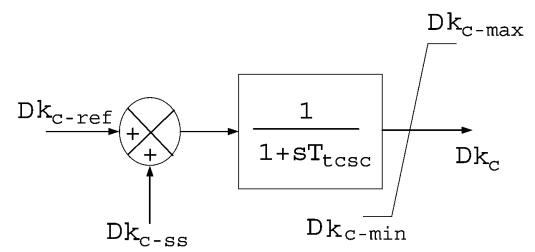

Fig. 2. Small-signal dynamic model of TCSC.

To facilitate the required power transfer, a TCSC device is installed in the line between buses \#18 and \#50. The small-signal dynamic model of the TCSC is shown in Fig. 2 (more details on this can be found in [15]). Eigen analysis, displayed in Table V, revealed the presence of four inter-area modes from which the first three are poorly damped requiring damping control action (details can be found in [8]). The TCSC controller (centralized) needs to provide supplementary damping control action to all critical inter-area modes of interest. The most effective measurements for control were found to be the power-flow signals in the lines between buses \#51-\#45 (P51;45), \#18-\#16 (P18;16), and \#13-\#17 (P13;17), respectively, [15] based on the results of the modal analysis. These are the lines which are carrying the amount of power from Area 3, Area 4, and the equivalent generation G13, respectively.

\section{B. Damping Control Design Objectives}

The designed controller should provide a minimum level of damping in the steady-state condition after a major disturbance in all the key interconnections. The aforementioned minimum level of damping corresponds to settling of inter-area oscillations within 10-15 s [1]. Power systems operate over a wide range of operating conditions and there is often uncertainty associated with the simulation models used for evaluating performance. Under these circumstances the controller should be robust and subject to having minimal sensitivity to various system operating conditions and component parameters. Moreover, interactions with high frequency phenomena, turbine-generator torsional vibration, and other resonances in the ac transmission network should be minimal.

\section{MODEL REDUCTION}

Modern control design methods such as LQG or $\mathcal{H}_{\infty}$, produce controllers of order at least equal to the order of the plant, and usually higher with the incorporation of the required extra weights. Model order reduction is required to simplify the design procedure and, thus, the complexity of the final controller. The reduced plant used in the design must be a good approximation of the full order equivalent, for appropriate control design. Hence, the central problem addressed is as follows.

Given a high-order linear model $G(s)$, derive a low-order approximation $G_{r}(s)$ such that the infinity norm of their difference $\left\|G-G_{r}\right\|_{\infty}$ is sufficiently small.

The same applies in the controller reduction approach. Our designs involved model and controller reduction based upon the Schur balanced model reduction procedure [16]. The reduction objective in this case is defined as follows.

Compute the $k$ th-order reduced model $G_{r}(s)=C_{r}(s I-$ $\left.A_{r}\right)^{-1} B_{r}+D_{r}$ from an $n$ th-order full model $G(s)=C(s I-$ $A)^{-1} B+D$ such that

$$
\left\|G-G_{r}\right\|_{\infty} \leq 2 \sum_{i=k+1}^{n} \sigma_{i}
$$


where $\sigma_{i}$ denotes the Hankel singular values of $G(j \omega)$, i.e., the square roots of the eigenvalues of their controllability and observability grammians (2)

$$
\sigma_{i}:=\sqrt{\lambda_{i}(P Q)}
$$

where $\lambda_{i}(P Q)$ is the $i$ th largest eigenvalue of $P Q$ and $P, Q$ are the solutions of the following Lyapunov equalities:

$$
\begin{aligned}
& P A^{T}+A P+B B^{T}=0 \text { (controllability grammian) } \\
& Q A+A^{T} Q+C^{T} C=0 \text { (observability grammian) }
\end{aligned}
$$

Note that $A, B, C$, and $D$ are the state space matrices of the full order model $G(s)$, while $A_{r}, B_{r}, C_{r}$, and $D_{r}$ are the state space matrices of the reduced-order model $G_{r}(s)$. In cases involving large number of state variables (i.e., $>1000$ ), one might have to employ numerical techniques, e.g., Krylov subspace-based technique, as the analytical techniques alone will not work.

\section{A. Remarks on Model Reduction for the Power System}

A realistic representation of the power system with supplementary damping controllers includes appropriate washout and signal transmission delay blocks. In this study, these blocks are chosen as

$$
\begin{aligned}
& V_{1}(s)=\frac{10 s}{10 s+1} \text { (washout) } \\
& V_{2}(s)=\frac{1}{1+0.1 s} \text { (signal transmission delay). }
\end{aligned}
$$

The designer can adjust the time constants of the previous filters in accordance with the actual disturbance caused typically by the adverse modes and measurement noise. However, performing model reduction on the plant incorporating these blocks proves insufficient in terms of correct approximation for all frequency ranges. The approach adopted in this work is, first, to reduce the order of the plant $G_{O}$ without the washout $\left(V_{1}\right)$ and delays $\left(V_{2}\right)$, and then merge the blocks $V_{2}, V_{1}$ into the reduced order equivalent $\hat{G}_{o}$. Note that in this case the order of the reduced model for design purposes-i.e., $V_{1} V_{2} \hat{G}_{o}$-will be increased due to the extra blocks, albeit the controller design will have essential information for the washout and signal delay characteristics.

The same washout and transmission delay blocks are assumed for each output channel, thus, without loss of generality these can be replaced by a single washout and a single delay block at the input channel for the design process.

A 9th-order reduced model $G_{r}$ (7 states from $\hat{G}_{o}$ and 2 states from the product $V_{2} \times V_{1}$ ) was found to be appropriate for control design. It includes both sufficient information for the main modes of interest and closed-loop stability. The comparison between the reduced- and full-order plants is illustrated in Fig. 3, where the reduced plant is a very good approximation especially within the frequency range of interest (by definition depicting the largest singular of the three output one input system transfer function). Note that the original model $G(s)$ was first scaled using a diagonal gain matrix, i.e., $\operatorname{diag}\{1.5,1.5,1\}$ for the design procedure (matrix $C$ is multiplied by the diagonal matrix

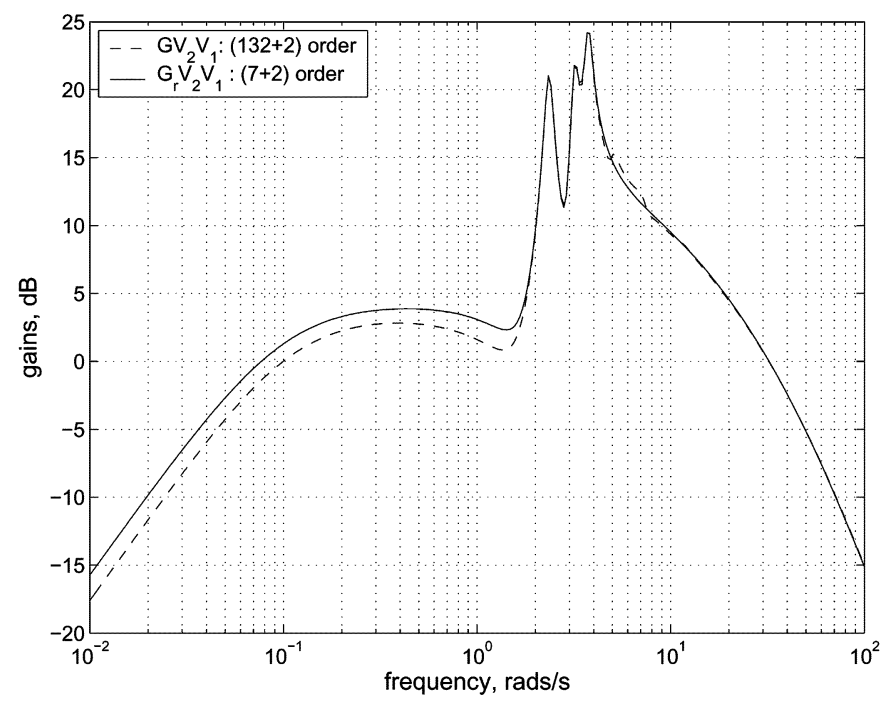

Fig. 3. Model reduction results.

before model reduction). This scaling is later incorporated in the designed controller. This is a usual practice in multivariable control as it makes model analysis and controller design (weight selection) much simpler [17].

\section{LQG/LTR DESIGN PRELIMINARIES}

The standard description of the plant and output is given by the following equations:

$$
\begin{aligned}
& \dot{\boldsymbol{x}}=A \boldsymbol{x}+B \boldsymbol{u}+\Gamma \boldsymbol{w} \\
& \boldsymbol{y}=C \boldsymbol{x}+\boldsymbol{\nu}
\end{aligned}
$$

where $\boldsymbol{x}$ is the $n$-dimensional state vector, $\boldsymbol{u}$ is the $m$-dimensional vector of inputs, and $y$ is the $q$-dimensional vector of outputs. The plant is assumed to be strictly proper, linear, time-invariant, controllable, and observable. Moreover, $\boldsymbol{w}$ and $\boldsymbol{\nu}$ are the process and sensor noise inputs, respectively, assumed uncorrelated white Gaussian noise processes with known covariance matrices $W$ and $V$, respectively [17].

The LQG control problem is then to obtain the optimal control $\boldsymbol{u}(\boldsymbol{t})$ which minimizes the following quadratic index:

$$
J=\lim _{T \rightarrow \infty} \frac{1}{T} E\left\{\int_{0}^{T}\left[z^{T} Q z+\boldsymbol{u}^{T} R \boldsymbol{u}\right] d \tau\right\}
$$

where $z$ can represent either $\boldsymbol{x}$ or a linear combination of the states (note that in practice it is appropriate to penalise certain output quantities rather than the full states for feasibility purposes). Matrices $Q$ and $R$ are appropriately chosen weighting parameters such that $Q^{T}=Q \geq 0$ and $R^{T}=R>0$. There are no specific guidelines concerning the form that $Q$ and $R$ should take, but in most cases they are diagonal matrices.

Next, we give a review of the LQG problem. The solution to the LQG control problem is prescribed by the separation principle [18]. This procedure reduces the problem into two subproblems, independent of each other, and is summarized as follows: 
- determine the optimal state-feedback control law [linear quadratic regulator (LQR) theory];

- obtain the estimates of the required states (Kalman filter theory).

Of course there is no restriction on which subproblem to solve first, either can be followed as required. However, the procedure adopted in this brief is first to solve the LQR problem and then to obtain the state estimates.

1) Thus, the optimal state-feedback control law is given by

$$
\boldsymbol{u}=-K_{c} \boldsymbol{x}
$$

where $K_{c}=R^{-1} B^{T} P_{c}$ and $P_{c}$ is the unique symmetric positive semidefinite solution of the algebraic Riccati equation (ARE)

$$
A^{T} P_{c}+P_{c} A+Q-P_{c} R^{-1} B^{T} P_{c}=0
$$

subject to $(A, B)$ being stabilizable, $R>0, Q \geq 0$, and $(Q, A)$ has no unobservable modes on the imaginary axis [19].

2) For practical implementation measuring all the states of the plant is infeasible, thus, an estimator (Kalman filter) is employed to provide the required estimates. The structure of the Kalman filter is that of an ordinary state-estimator with

$$
\dot{\hat{\boldsymbol{x}}}=A \hat{\boldsymbol{x}}+B \boldsymbol{u}+K_{f}(\boldsymbol{y}-C \hat{\boldsymbol{x}}) .
$$

$K_{f}$ is the Kalman filter gain minimizing $E\left\{[\boldsymbol{x}-\hat{\boldsymbol{x}}]^{T}[\boldsymbol{x}-\right.$ $\hat{\boldsymbol{x}}]$ \}, given by

$$
K_{f}=P_{f} C^{T} V^{-1}
$$

where $P_{f}$ is the unique symmetric positive semidefinite solution of the following are:

$$
P_{f} A^{T}+A P_{f}-P_{f} C^{T} V^{-1} C P_{f}+\Gamma W \Gamma^{T}=0
$$

subject to $(C, A)$ being detectable, $V>0, W \geq 0$, and $\left(A, \Gamma W \Gamma^{T}\right)$ has no uncontrollable modes on the imaginary axis. In fact, the optimum estimation problem is dual to the deterministic optimum control problem [19], [20]. Finally, the optimal control law in the LQG formulation becomes

$$
\boldsymbol{u}=-K_{c} \hat{\boldsymbol{x}}
$$

It can be shown from the previous list that $Q, R, W$, and $V$ are "tuning parameters" to be adjusted until an acceptable design arises, although choosing these parameters requires a great deal of experience and also trial-and-error. An extensive discussion on this matter can be found in [21], where a number of insights into choosing the weighting matrices is investigated. A rather practical approach on selecting weighting matrices is discussed in [22]. The LQG scheme is depicted in Fig. 4.

\section{A. Loop Transfer Recovery (LTR)}

Unfortunately the LQG compensators do not exhibit the good robustness properties of both the LQR and Kalman filter as

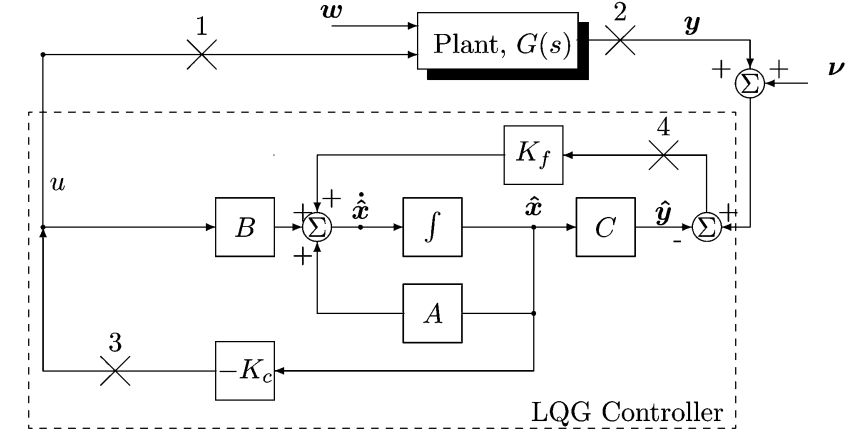

Fig. 4. LQG controller configuration.

demonstrated in [23] and [24]. However, there is a way of either designing the Kalman filter such that the LQR robustness properties are "recovered" at the plant input; or designing the LQR such that the Kalman filter robustness properties are recovered at the plant output. The LTR procedure is extensively discussed in [24]-[26].

The main points of the procedure are summarized as follows (with respect to Fig. 4).

1) Recovery at plant input. Design the Kalman filter gain $K_{f}$ such that the loop TF $K(s) G(s)$ (point 1) approaches $K_{c}(s I-A)^{-1} B$ (point 3) [24]. The plant must have at least as many outputs as inputs. In order for LTR to be applied, fictitious inputs must be included to make the system square and minimum phase (see Section V). Recovery can be followed at plant input but not plant output [18]. This is the approach undertaken in this brief.

2) Recovery at plant output. Design the LQR gain $K_{c}$ such that the loop TF $G(s) K(s)$ (point 2) approaches $C(s I-$ $A)^{-1} K_{f}$ (point 4 ). In this case, artificial outputs must be included to make the system square and minimum phase. However, recovery can be applied only at plant output and not plant input [18].

In both cases the plant is assumed to be minimum phase for full recovery. In the case of nonminimum phase systems, the same procedure can be used but only to partially recover the required robustness properties for a specific range of frequencies (only partial recovery is achieved even in the case of minimum phase systems in a practical implementation). More details on LTR for nonminimum phase systems can be found in [26] and [27].

Note that LTR is a virtual design procedure (using fictitious noise inputs), thus, extra care should be taken when recovering the required robustness properties. Care should be taken for the required level of robustness to be achieved, due to the fact that full recovery would undoubtedly deteriorate the nominal performance of the true noise problem [28].

\section{Minimum-Phase Square Plant Augmentation}

In this part, we give an outline of a procedure regarding the minimum-phase augmentation required for appropriate LTR procedure. This relates to making the plant square, minimum-phase and, in addition, prescribe a minimum damping for the resultant transmission zeros of the square plant. 
Given a transfer matrix

$$
G_{1}(s) \stackrel{s}{=} \underset{p}{n}\left[\begin{array}{c|c}
n & p_{1} \\
\hline C & B_{1} \\
\hline C & 0
\end{array}\right]
$$

with $p>p_{1}$, find $B_{2} \in \mathcal{R}^{n \times p_{2}}$, with $p=p_{1}+p_{2}$, so that

$$
G_{1}(s)=\left[\begin{array}{ll}
G_{1}(s) & G_{2}(s)
\end{array}\right] \stackrel{s}{=} \underset{p}{n}\left[\begin{array}{c|c||c}
n & p_{1} & p_{2} \\
\hline C & B_{1} & B_{2} \\
\hline C & 0 & 0
\end{array}\right]
$$

is minimum-phase. We assume that the realization for $G_{1}(s)$ is minimum-phase since $G(s)$ is minimum-phase only if $G_{1}(s)$ is. Since $\operatorname{rank}(G(s)) \leq \operatorname{rank}(C)$, we will assume that $\operatorname{rank}(C)=$ $p$. We also assume that $G_{1}(s)$ has normal rank $p_{1}$. The last two assumptions imply that $G_{1}(s)$ and $G(s)$ are nondegenerate [29]. These assumptions can be relaxed, however, this will greatly complicate the presentation.

We will make use of the following result which is a simple adaptation of [30, corollary 7.7].

Lemma 5.1: Suppose that

$$
G_{1}(s) \stackrel{s}{=} \underset{p}{n}\left[\begin{array}{l|l}
n & p_{1} \\
\hline C & B_{1} \\
\hline C & D_{1}
\end{array}\right]
$$

with $p>p_{1}$, is minimum-phase and assume that $D_{1}$ has full column rank. Then, there exists $B_{2} \in \mathcal{R}^{n \times p_{2}}$ and $D_{2} \in \mathcal{R}^{p \times p_{2}}$, where $p=p_{1}+p_{2}$, such that

$$
G(s)=\left[\begin{array}{ll}
G_{1}(s) & G_{2}(s)
\end{array}\right] \stackrel{s}{=} \underset{p}{n}\left[\begin{array}{c|c||c}
n & p_{1} & p_{2} \\
\hline C & B_{1} & B_{2} \\
\hline D_{1} & D_{2}
\end{array}\right]
$$

is minimum-phase.

We cannot directly use Lemma 5.1 since, in our case, $D_{1}=$ 0 , and we require $D_{2}=0$. Instead, we proceed as follows. Since $\operatorname{rank}(C)=p$, there exists an orthogonal similarity transformation $V \in \mathcal{R}^{n \times n}$ such that

$$
\begin{aligned}
G_{1}(s) & \stackrel{s}{=} \underset{p}{n}\left[\begin{array}{c|c}
V^{T} A V & p_{1} \\
\hline C V & \multicolumn{2}{c}{0}
\end{array}\right] \\
& =\underset{p}{p} B_{1} p \\
p & {\left[\begin{array}{cc|c}
A_{11} & A_{12} & B_{11} \\
A_{21} & A_{22} & B_{21} \\
\hline C_{11} & 0 & 0
\end{array}\right] }
\end{aligned}
$$

where $C_{11} \in \mathcal{R}^{p \times p}$ is nonsingular. It follows that there are at most $n-p$ finite (system) zeros of $G_{1}(s)$ which are the zeros of

$$
\begin{array}{c|c}
n-p & p_{1} \\
p-p & {\left[\begin{array}{l|l}
A_{22} & B_{21} \\
\hline A_{12} & B_{11}
\end{array}\right] .}
\end{array}
$$

(Refer to [29] for a detailed discussion of zeros for linear multivariable systems.) If $B_{11}$ has full column rank, we are done, since we can use Lemma 5.1 to construct the minimum-phase augmentation

$$
\begin{aligned}
& n \\
& p
\end{aligned}\left[\begin{array}{c|c||c}
n & p_{12} & p_{2} \\
\hline A_{12} & B_{21} & B_{22} \\
\hline A_{11} & B_{12}
\end{array}\right]
$$

and then $B_{2}=V\left[\begin{array}{l}B_{12} \\ B_{22}\end{array}\right]$. If $B_{11}$ does not have full column rank, we redefine

$$
G_{1}(s) \stackrel{s}{=} \underset{p}{p}\left[\begin{array}{c|c}
n & p_{1} \\
\hline C & B_{1} \\
\hline C & D_{1}
\end{array}\right]:=\begin{gathered}
n-p \\
p
\end{gathered}\left[\begin{array}{ll}
A_{22} & B_{21} \\
\hline A_{12} & B_{11}
\end{array}\right]
$$

and use the next result which is an adaptation of Algorithm REDUCE and [31, Th. 1].

Lemma 5.2: Suppose that $G_{1}(s)$ has a realization given by (17) with $p>p_{1}$ and assume that $G_{1}(s)$ has normal (column) rank $p_{1}$. Then there exists

$$
\hat{G}_{1}(s) \stackrel{s}{=} \begin{array}{c|c}
\hat{n} \\
p
\end{array}\left[\begin{array}{c|c}
\hat{n} & p_{1} \\
\hline \hat{A} & \hat{B}_{1} \\
\hline \hat{C} & \hat{D}_{1}
\end{array}\right]
$$

of normal rank $p_{1}$ with $\hat{n} \leq n$, which has the same finite zeros as $G_{1}(s)$ such that $\hat{D}_{1}$ has full rank.

Since $\hat{G}_{1}(s)$ is minimum-phase and $\hat{D}_{1}$ has full column rank, we can now use Lemma 5.1 to define a minimum-phase augmentation for $\hat{G}_{1}$ and reverse all transformations to obtain the required minimum-phase augmentation for $G_{1}(s)$. The procedure is straightforward but rather long and we, therefore, omit the details.

\section{Centralized Control Method}

\section{A. Solution of the LQR Problem}

The design of the optimal control gain $K_{c}$ was based on the 9th-order, reduced-order scaled model $G_{r}(s)$ discussed in Section III, with state variables $x_{r}=\left[x_{r_{1}}, x_{r_{2}}, \ldots, x_{r_{9}}\right]^{T}$. As mentioned previously, the diagonal scaling matrices are merged with the controller in the final stage of the design procedure [32].

Since the design is based on the reduced-order system there is no direct systematic way for choosing the weighting matrices, thus, an ad hoc procedure was followed in order to achieve the design specifications. An initial guess for the state-weighting matrix $Q$ can be chosen via a participation factor analysis [33] on $G_{r}(s)$, by overall investigating the state participation in each of the three oscillatory modes (as shown in Table I). The states participating most in each of the three oscillatory modes are shown in boldface, with state no. 3 appearing in all three oscillatory modes and state no. 6 appearing in the first and second oscillatory mode. The initial state weighting for states no. 6 and 3 was set to an arbitrary value of 10 (as their participation influences all three modes), while the state-weighting for the remaining states was set to an arbitrary value of 1 . The aim was to initially investigate the effect of pronouncing the state-weight of states no. 6 and 3 for improving the damping in all three modes 
TABLE I

PARTICIPATION FACTOR ANALYSIS FOR THE REDUCED-ORDER PLANT

\begin{tabular}{|c|c||c|c||c|r|}
\hline \multicolumn{2}{|c||}{$\begin{array}{c}\text { Mode 1 } \\
\text { @ } 0.373 \mathrm{~Hz}\end{array}$} & \multicolumn{2}{c||}{$\begin{array}{c}\text { Mode 2 } 0.505 \mathrm{~Hz} \\
\text { Mode 3 } \\
0.50 .594 \mathrm{~Hz}\end{array}$} \\
\hline \hline state no. & particip. & state no. & particip. & state no. & particip. \\
\hline $\mathbf{6}$ & $\mathbf{0 . 3 1 6}$ & $\mathbf{2}$ & $\mathbf{0 . 2 4 9}$ & $\mathbf{4}$ & $\mathbf{0 . 5 3 1}$ \\
\hline $\mathbf{3}$ & $\mathbf{0 . 3 1 4}$ & $\mathbf{6}$ & $\mathbf{0 . 2 4 1}$ & $\mathbf{3}$ & $\mathbf{0 . 2 2 1}$ \\
\hline $\mathbf{7}$ & $\mathbf{0 . 2 4 0}$ & $\mathbf{3}$ & $\mathbf{0 . 2 3 1}$ & $\mathbf{5}$ & $\mathbf{0 . 1 9 9}$ \\
\hline 1 & 0.063 & $\mathbf{7}$ & $\mathbf{0 . 1 8 6}$ & 2 & 0.025 \\
\hline 2 & 0.033 & 1 & 0.043 & 6 & 0.012 \\
\hline 4 & 0.023 & 4 & 0.038 & 7 & 0.009 \\
\hline 5 & 0.011 & 5 & 0.014 & 1 & 0.003 \\
\hline
\end{tabular}

TABLE II

EIGENVALUES OF OPEN-LOOP AND “IDEAL" Closed-LOOP FOR REDUCED PLANT INCL. $V_{2}, V_{1}$

\begin{tabular}{|c||cc|}
\hline $\begin{array}{c}\text { Open-Loop } \\
A_{r}\end{array}$ & 'Ideal' Closed-Loop \\
& $A_{r}-B_{r} K_{c}$ \\
\hline eig-value & eig-value & \\
\hline-0.1 & -0.13 \\
\hline$-\mathbf{0 . 1 2} \pm \mathbf{2 . 3 4 j}$ & $-\mathbf{0 . 4 3} \pm \mathbf{2 . 3 5} \mathbf{j}$ & (mode 1) \\
\hline$-\mathbf{0 . 1 4} \pm \mathbf{3 . 1 7} \mathbf{j}$ & $-\mathbf{0 . 4 8} \pm \mathbf{3 . 2 3} \mathbf{j}$ & (mode 2) \\
\hline$-\mathbf{0 . 1 8 5} \pm \mathbf{3 . 7 3} \mathbf{j}$ & $-\mathbf{0 . 7 0 4} \pm \mathbf{3 . 7 3} \mathbf{j}$ & (mode 3) \\
\hline-10 & -10.6 & \\
\hline-48.9 & -48.8 \\
\hline
\end{tabular}

and subsequently fine-tune all state-weights to get the desired result.

The control-weighting matrix $R$ was fixed to a value of $1 /(\text { expected value })^{2}$ of the control parameter [34]. The final values, for $Q$ and $R$ were chosen as

$$
Q=\operatorname{diag}\{1,25,2, .1,1,2,2,1,1\}, \quad R=\frac{1}{0.15^{2}} .
$$

It is worth mentioning that the two states introduced from the washout $V_{1}$ and delay $V_{2}, x_{r_{8}}$, and $x_{r_{9}}$, respectively, do not participate in the modes (they are not shown in Table I). This is due to the way chosen to incorporate the blocks in the reduced model for the design (there are alternative ways of blending these blocks in the model, however, the simplest was used in this brief). Note that for design purposes their state-weight is set to an arbitrary nominal value of 1 .

It can be shown from Table I that the highest participation factors for mode 2 (at $0.505 \mathrm{~Hz}$ ) are less pronounced compared to their participations for the other two modes (mode 1 and mode 3 ). It was essential to increase the value of the weight of $x_{r_{2}}$ in $Q$ in order to improve the required amount of damping for the second mode, while keeping the damping of the first and third modes within normal limits by slightly adjusting the weighting of the remaining states. State $x_{r_{2}}$ has the highest participation factor for mode 2 and only a secondary (participation) effect for modes 1 and 3 . Thus, it was found that by mainly tuning this state-weight an appropriate damping ratio can be set for all modes, which makes the tuning procedure easier. Increasing the weights for the other main states as shown in Table I provides very high damping ratios for the first and third mode, while fails to improve the damping for the second mode. Interestingly, there is a tradeoff between increasing the damping of the second mode compared to the damping of the first and third mode.

Table II presents the "ideal" eigenvalues for the closed-loop based upon the reduced-order system using LQR state feedback, i.e., $\operatorname{eig}\left(A_{r}-B_{r} K_{c}\right)$. The corresponding $\mathrm{LQR}$ gain $K_{c}$ for the weights in (24) is

$K_{c}=[-1.44,0.59,0.38,0.13,-0.25,-0.15,0.73,0.13,0.71]$.

The inter-area modes are shown in bold typeface in Table II.

\section{B. Kalman Filter Design/Loop Transfer Recovery on the Reduced-Order Plant}

The next step is to design the Kalman estimator to recover the LQR robust properties at the plant input (point "1" of Fig. 4). Thus, the reduced plant is made square by adding two extra "dummy" or "artificial" inputs such that LTR can be applied as discussed in previous sections. Thus the "amended" plant for the Kalman filter design is

$$
\begin{aligned}
& \dot{\boldsymbol{x}}_{\boldsymbol{r}}=A_{r} \boldsymbol{x}_{\boldsymbol{r}}+\left[B_{r} \tilde{B}_{r}\right]\left[\boldsymbol{u}^{T} \tilde{\boldsymbol{u}}^{T}\right]^{T}+\Gamma_{r} \boldsymbol{w} \\
& \boldsymbol{y}_{\boldsymbol{r}}=C_{r} \boldsymbol{x}_{\boldsymbol{r}}+\left[D_{r} \tilde{D}_{r}\right]\left[\boldsymbol{u}^{T} \tilde{\boldsymbol{u}}^{T}\right]^{T}+\boldsymbol{\nu}
\end{aligned}
$$

where $\tilde{B}_{r}, \tilde{D}_{r}$ are the matrices corresponding to the extra fictitious inputs. Moreover, $\tilde{D}_{r}=0_{3 \times 2}$ while $\tilde{B}_{r}$ can be chosen such that $C_{r}\left(s I-A_{r}\right)^{-1}\left[B_{r} \tilde{B}_{r}\right]$ is minimum phase and in addition has no lightly damped zeros (see section on "minimumphase square augmentation"). It must be noted that LQG controllers follow the optimal root loci, i.e., controller poles start from the open-loop poles of the system and approach the openloop system zeros as gains increase towards infinity [21], [24]. Thus, any lightly damped open-loop system zeros will impose difficult constraints on LTR especially for the application of power oscillations damping improvement. The procedure for choosing the matrices for fictitious inputs or outputs is discussed in Section V.

For design completeness, the LQR gain $K_{c}$ is amended by adding two zero rows corresponding to the fictitious inputs, i.e., $\left[\begin{array}{lll}K_{c}^{T} & 0^{T} & 0^{T}\end{array}\right]^{T}$. Thus, these extra inputs will have no effect upon the final LQG controller. Following the LTR procedure suggested in [24], the process and measurement noise covariances $W, V$ are treated as the following "free tuning" parameters:

$$
\begin{aligned}
W & =\Gamma_{r} W_{o} \Gamma_{r}^{T}+q^{2}\left[B_{r} \tilde{B}_{r}\right] \Theta\left[B_{r} \tilde{B}_{r}\right]^{T} \\
V & =V_{o}
\end{aligned}
$$

where $W_{o}$ and $V_{o}$ are noise covariances relative to the nominal model and $\Theta$ any positive definite symmetric matrix. Setting $q=0$ involves no recovery and this corresponds to the nominal Kalman filter gain, while for $q \rightarrow \infty$ full recovery applies. The second term on the right-hand side of (28) corresponds to additional process noise which enters directly to the control input.

\section{Application of LTR}

Fig. 5 shows the LTR procedure for $q=0,1,5,10,100$. The measurement noise covariance $V_{o}=0.01 \times I_{3 \times 3}$, is chosen quite low in order to depict the characteristics of high quality sensor equipment. The other values of the tuning parameters for the Kalman filter LTR design in (28) were set to fixed values of

$$
\Gamma_{r}=I_{9 \times 9}, \quad \Theta=I_{3 \times 3}, \quad W_{o}=I_{9 \times 9} .
$$

The controller used to produce the results in Fig. 5 is the full 9 th-order for purposes of appropriate comparison. For the rest of the design $q$ was set to a fixed value of 10 , which involves 


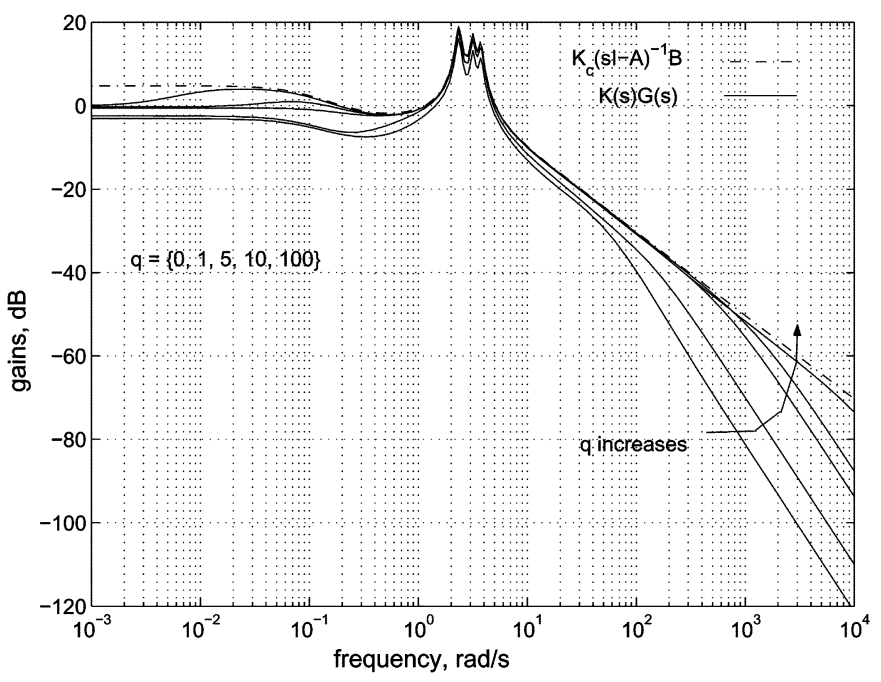

Fig. 5. LTR method at plant input for various $q$ parameter values.

TABLE III

Kalman Estimator Poles FOR $q=10$ (Ninth ORdeR) VERSUS OL TRANSMISSION ZEROS OF $C_{r}\left(s I-A_{r}\right)^{-1}\left[B_{r} \tilde{B}_{r}\right]$

\begin{tabular}{|c||c||c|}
\hline Row no. & Kalman filter poles & Transmission zeros \\
$A_{r}-K_{f} C_{r}$ & $C_{r}\left(s I-A_{r}\right)^{-1}\left[B_{r} \tilde{B}_{r}\right]$ \\
\hline \hline 1 & -0.0463 & $\sim 0$ \\
\hline 2 & $-0.93 \pm 2.06 j$ & $-0.92 \pm 2.04 j$ \\
\hline 3 & -2.39 & -2.39 \\
\hline 4 & $-29.8 \pm 17.5 j$ & $\mathrm{n} / \mathrm{a}$ \\
\hline 5 & -143.00 & -178.94 \\
\hline 6 & -220.00 & $\mathrm{n} / \mathrm{a}$ \\
\hline 7 & -1410.00 & $\mathrm{n} / \mathrm{a}$ \\
\hline
\end{tabular}

sufficient recovery within the frequency range of interest and a faster roll-off at high frequencies compared to $q=100$.

Table III illustrates the location of the transmission zeros for the Kalman filter compared to the open-loop transmission zeros of the squared/minimum-phase design system (minimum damping ratio assigned is 0.45 ). The Kalman gain vector $K_{f}$ is given by (31). Note that the poles in rows $1,2,3$, and 5 approach the OL transmission zeros (defined to be minimum phase and well-damped), while the remaining poles in rows 4 , 6 , and 7 ultimately will move towards $-\infty$ as $q \rightarrow \infty$ (from optimal root loci as discussed earlier)

$$
K_{f}=\left[\begin{array}{ccc}
-39.13 & -102.30 & -38.85 \\
-19.58 & 19.86 & -23.61 \\
-0.74 & -79.57 & 62.32 \\
-53.10 & -107.96 & -132.24 \\
-191.90 & 64.42 & -34.15 \\
25.93 & 60.97 & -118.52 \\
-54.27 & -137.71 & -20.99 \\
-18.17 & -49.34 & 29.64 \\
277.40 & -243.14 & -126.59
\end{array}\right]
$$

\section{LQG Controller Reduction}

The designed LQG controller, with its transfer function given in (32), is of 9th order equal to the order of the design (reduced) plant. It is desired to reduce the controller size further, while satisfying the required damping ratios for the inter-area modes

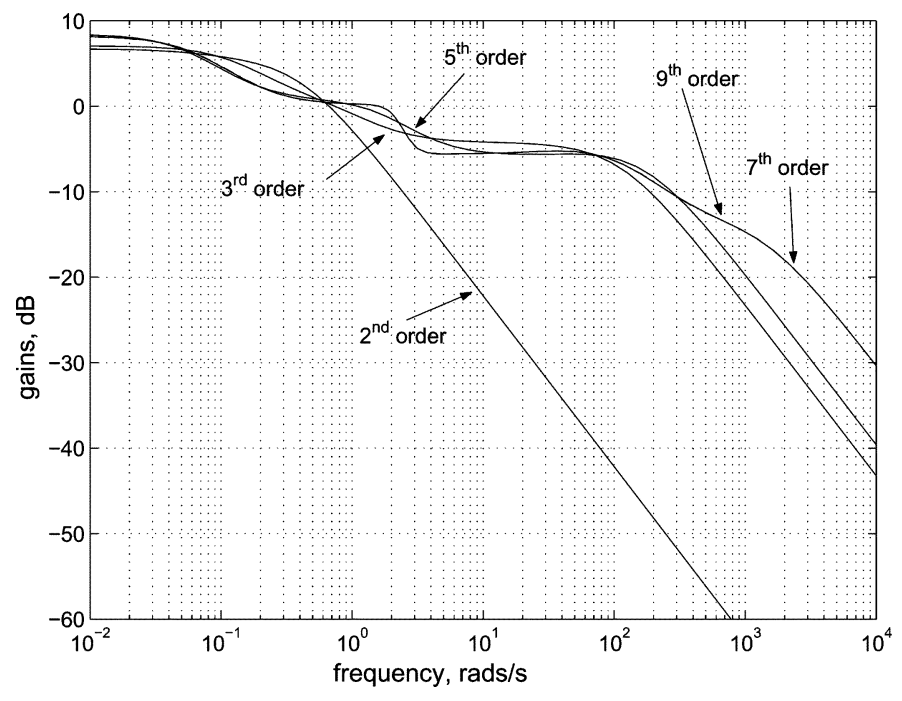

Fig. 6. Singular value plot of controller approximation.

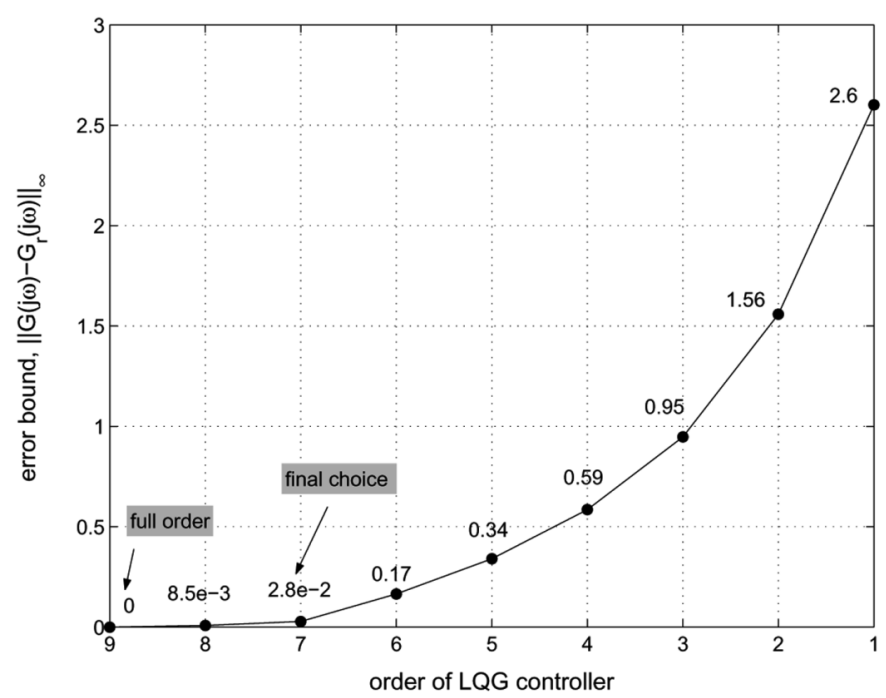

Fig. 7. Controller reduction error bound.

TABLE IV

Closed-LoOP System With 138Th-ORder Plant AND (I) FULL $K(s)$, (II) REDUCED $K(s)$

\begin{tabular}{|c|c||c|c||c|r|}
\hline \multicolumn{2}{|c||}{} & \multicolumn{2}{c||}{ Closed-loop with } & \multicolumn{2}{c|}{ Closed-loop with } \\
\multicolumn{2}{|c|}{} & $K(s) 9^{t h}$ order & $K(s) 7^{t h}$ order \\
\hline \hline & mode no. & $\zeta$ & $f(H z)$ & $\zeta$ & $f(H z)$ \\
\cline { 2 - 6 } Pre- & $\mathbf{1}$ & $\mathbf{0 . 1 5 5}$ & $\mathbf{0 . 4 1 0}$ & $\mathbf{0 . 1 4 8}$ & $\mathbf{0 . 4 1 4}$ \\
\cline { 2 - 6 } FAU & $\mathbf{2}$ & $\mathbf{0 . 1 6 7}$ & $\mathbf{0 . 5 1 2}$ & $\mathbf{0 . 1 6 8}$ & $\mathbf{0 . 5 1 4}$ \\
\cline { 2 - 6 } LT & $\mathbf{3}$ & $\mathbf{0 . 1 6 1}$ & $\mathbf{0 . 6 5 0}$ & $\mathbf{0 . 1 4 7}$ & $\mathbf{0 . 6 5 2}$ \\
\cline { 2 - 6 } & 4 & 0.074 & 0.790 & 0.074 & 0.791 \\
\hline \hline Post- & $\mathbf{1}$ & $\mathbf{0 . 1 4 3}$ & $\mathbf{0 . 3 7 7}$ & $\mathbf{0 . 1 4 5}$ & $\mathbf{0 . 3 8 1}$ \\
\cline { 2 - 6 } FAU & $\mathbf{2}$ & $\mathbf{0 . 1 1 1}$ & $\mathbf{0 . 5 2 7}$ & $\mathbf{0 . 1 1 4}$ & $\mathbf{0 . 5 2 6}$ \\
\cline { 2 - 6 } LT & $\mathbf{3}$ & $\mathbf{0 . 2 1 4}$ & $\mathbf{0 . 6 1 1}$ & $\mathbf{0 . 1 9 0}$ & $\mathbf{0 . 6 2 0}$ \\
\cline { 2 - 6 } & 4 & 0.075 & 0.790 & 0.075 & 0.792 \\
\hline
\end{tabular}

for the full power network model. The reduction process uses the Schur balanced reduction method as discussed in Section III

$$
K_{l q g} \stackrel{s}{=}\left[\begin{array}{c|c}
A_{r}-B_{r} K_{c}-K_{f} C_{r} & K_{f} \\
\hline-K_{c} & 0
\end{array}\right]
$$


TABLE V

Damping Ratios for Prefault and Post-Fault Conditions With 700 MW Flow Between NETS and NYPS and CI LOAD Model

\begin{tabular}{|c||c|c|c|c||c|c|c|c|}
\hline \multirow{2}{*}{ Mode } & \multicolumn{4}{|c||}{ Pre-fault } & \multicolumn{4}{c|}{ Post-fault } \\
\cline { 2 - 9 } & \multicolumn{2}{|c|}{ Open-loop } & \multicolumn{2}{c|}{ Closed-loop } & \multicolumn{2}{c|}{ Open-loop } & \multicolumn{2}{c|}{ Closed-loop } \\
\cline { 2 - 9 } & $\zeta$ & $f(H z)$ & $\zeta$ & $f(H z)$ & $\zeta$ & $f(H z)$ & $\zeta$ & $f(H z)$ \\
\hline \hline $\mathbf{1}$ & 0.063 & 0.391 & $\mathbf{0 . 1 5 1}$ & 0.415 & 0.051 & 0.373 & $\mathbf{0 . 1 5 1}$ & 0.381 \\
\hline $\mathbf{2}$ & 0.044 & 0.508 & $\mathbf{0 . 1 7 4}$ & 0.514 & 0.042 & 0.507 & $\mathbf{0 . 1 1 6}$ & 0.526 \\
\hline $\mathbf{3}$ & 0.055 & 0.623 & $\mathbf{0 . 1 5 8}$ & 0.649 & 0.047 & 0.594 & $\mathbf{0 . 2 0 6}$ & 0.617 \\
\hline $\mathbf{4}$ & 0.050 & 0.792 & $\mathbf{0 . 0 7 7}$ & 0.789 & 0.050 & 0.791 & $\mathbf{0 . 0 7 7}$ & 0.789 \\
\hline
\end{tabular}

TABLE VI

Damping Ratios at Different LeVels of Power Flows With CI LOAD Model and Between NETS and NYPS Under PREFAULt Condition

\begin{tabular}{|c||c|c|c|c|c|c|c|c|}
\hline \multicolumn{1}{|c||}{ Power flow } & \multicolumn{2}{c|}{ Mode 1 } & \multicolumn{2}{c|}{ Mode 2 } & \multicolumn{2}{c|}{ Mode 3 } & \multicolumn{2}{c|}{ Mode 4 } \\
\cline { 2 - 9 } NETS-NYPS(MW) & $\zeta$ & $f(H z)$ & $\zeta$ & $f(H z)$ & $\zeta$ & $f(H z)$ & $\zeta$ & $f(H z)$ \\
\hline \hline $\mathbf{1 0 0}$ & 0.131 & 0.429 & 0.211 & 0.507 & 0.139 & 0.671 & 0.077 & 0.789 \\
\hline $\mathbf{5 0 0}$ & 0.146 & 0.421 & 0.188 & 0.510 & 0.150 & 0.659 & 0.077 & 0.789 \\
\hline $\mathbf{7 0 0}$ & 0.151 & 0.415 & 0.174 & 0.514 & 0.158 & 0.650 & 0.077 & 0.789 \\
\hline $\mathbf{9 0 0}$ & 0.153 & 0.408 & 0.158 & 0.518 & 0.169 & 0.639 & 0.076 & 0.789 \\
\hline
\end{tabular}

TABLE VII

DAMPING RATIOS FOR DifFERENT LOAD CHARACTERISTICS WITH 700 MW FlOW BETWEEN NETS AND NYPS UNDER PREFAULT CONDITION

\begin{tabular}{|c|c|c|c|c|c|c|c|c|}
\hline \multirow{2}{*}{$\begin{array}{l}\text { Type of } \\
\text { load model }\end{array}$} & \multicolumn{2}{|c|}{ Mode 1} & \multicolumn{2}{|c|}{ Mode 2} & \multicolumn{2}{|c|}{ Mode 3} & \multicolumn{2}{|c|}{ Mode 4} \\
\hline & $\zeta$ & $f(H z)$ & $\zeta$ & $f(H z)$ & $\zeta$ & $f(H z)$ & $\zeta$ & $f(H z)$ \\
\hline CI & 0.151 & 0.415 & 0.174 & 0.514 & 0.158 & 0.650 & 0.077 & 0.789 \\
\hline $\mathrm{CC}+\mathrm{CI}$ & 0.132 & 0.418 & 0.191 & 0.530 & 0.163 & 0.639 & 0.077 & 0.789 \\
\hline $\mathrm{CP}+\mathrm{CI}$ & 0.122 & 0.418 & 0.216 & 0.552 & 0.156 & 0.627 & 0.077 & 0.790 \\
\hline Dynamic* & 0.156 & 0.410 & 0.185 & 0.519 & 0.158 & 0.647 & 0.080 & 0.790 \\
\hline
\end{tabular}

TABLE VIII

Damping Ratios for Outage of Different Tie-Lines With 700 MW Flow BetweEn NETS AND NYPS AND CI LOAD MODEL

\begin{tabular}{|c||c|c|c|c|c|c|c|r|}
\hline \multirow{2}{*}{$\begin{array}{c}\text { Outage of tie } \\
\text {-line between }\end{array}$} & \multicolumn{2}{|c|}{ Mode 1 } & \multicolumn{2}{c|}{ Mode 2 } & \multicolumn{2}{c|}{ Mode 3 } & \multicolumn{2}{c|}{ Mode 4 } \\
\cline { 2 - 9 } & $\zeta$ & $f(\mathrm{~Hz})$ & $\zeta$ & $f(\mathrm{~Hz})$ & $\zeta$ & $f(\mathrm{~Hz})$ & $\zeta$ & $f(\mathrm{~Hz})$ \\
\hline \hline $\mathbf{6 0 - 6 1}$ & 0.141 & 0.385 & 0.101 & 0.526 & 0.220 & 0.606 & 0.076 & 0.789 \\
\hline $\mathbf{5 3 - 5 4}$ & 0.151 & 0.381 & 0.116 & 0.526 & 0.206 & 0.617 & 0.077 & 0.789 \\
\hline $\mathbf{2 7 - 5 3}$ & 0.158 & 0.404 & 0.156 & 0.518 & 0.173 & 0.638 & 0.077 & 0.789 \\
\hline
\end{tabular}

where $A_{r}, B_{r}$, and $C_{r}$ are the state space matrices of the reduced-order plant for the design $\left(D_{r}=0\right)$. Fig. 6 presents the singular value plot for a number of reduced size controller choices compared to the initial 9th-order designed controller. In addition, Fig. 7 presents the error bound (the infinity norm of the difference between full and reduced controller) for a number of reduced size controller choices.

It can be shown from Fig. 6 that the 7th-order controller is nearly indistinguishable compared to the original 9th order, while deterioration starts occurring as the order is further reduced. This is further justified in Fig. 7, where it can be clearly shown that after the choice of the 7th-order controller, the error bound is substantially increasing.

Table IV illustrates the damping of the inter-area modes of the closed loop using the 9th- and 7th-order controller. Note that in this case the plant model used is the full order equivalent with the total washout and signal delay blocks $(132+6$ states $)$.

\section{Performance Assessment of Designed System}

The performance of the designed system is mainly assessed via eigen-analysis and time domain simulations, as shown in the results of Tables V-VIII and Figs. 8 and 9, for a variety of operating conditions. It is evident from the results obtained that the damping ratios of the inter-area modes in the presence of the control action are improved substantially compared to the uncontrolled case. The system in this case is the full 138th order while the controller is the 7th-order equivalent. Table $\mathrm{V}$ presents the eigen-analysis results for open-loop and closed-loop under both prefault and post-fault conditions. The controlled system is characterized by satisfactory damping for modes \#1, \#2, and \#3 (bold-face) in all cases (although it was designed based upon the post-fault model). Table VI shows the damping ratios and related frequency of the inter-area modes when the NETS-toNYPS power flow varies in the range of $100-900$ MW. It is again verified that the controlled system provides substantial damping under all conditions. Moreover, the performance of the controller was further evaluated for different load conditions Table VII, and different line outages scenaria Table VIII. It is clearly shown that the controller maintains good robustness properties under probable conditions.

A nonlinear Matlab simulation was executed over a timelength of $25 \mathrm{~s}$ to further demonstrate robust performance of the controller in the presence of nonlinearities inclusive of possible saturation. Inter-area oscillations are initiated due to a threephase solid fault close to bus \#53 on one of the tie-lines connecting buses \#53-\#54. Fig. 8 displays the system dynamic response in terms of the relative angular separation of machine G1 relative to G15 and machines G14, G15, and G16 relative to 

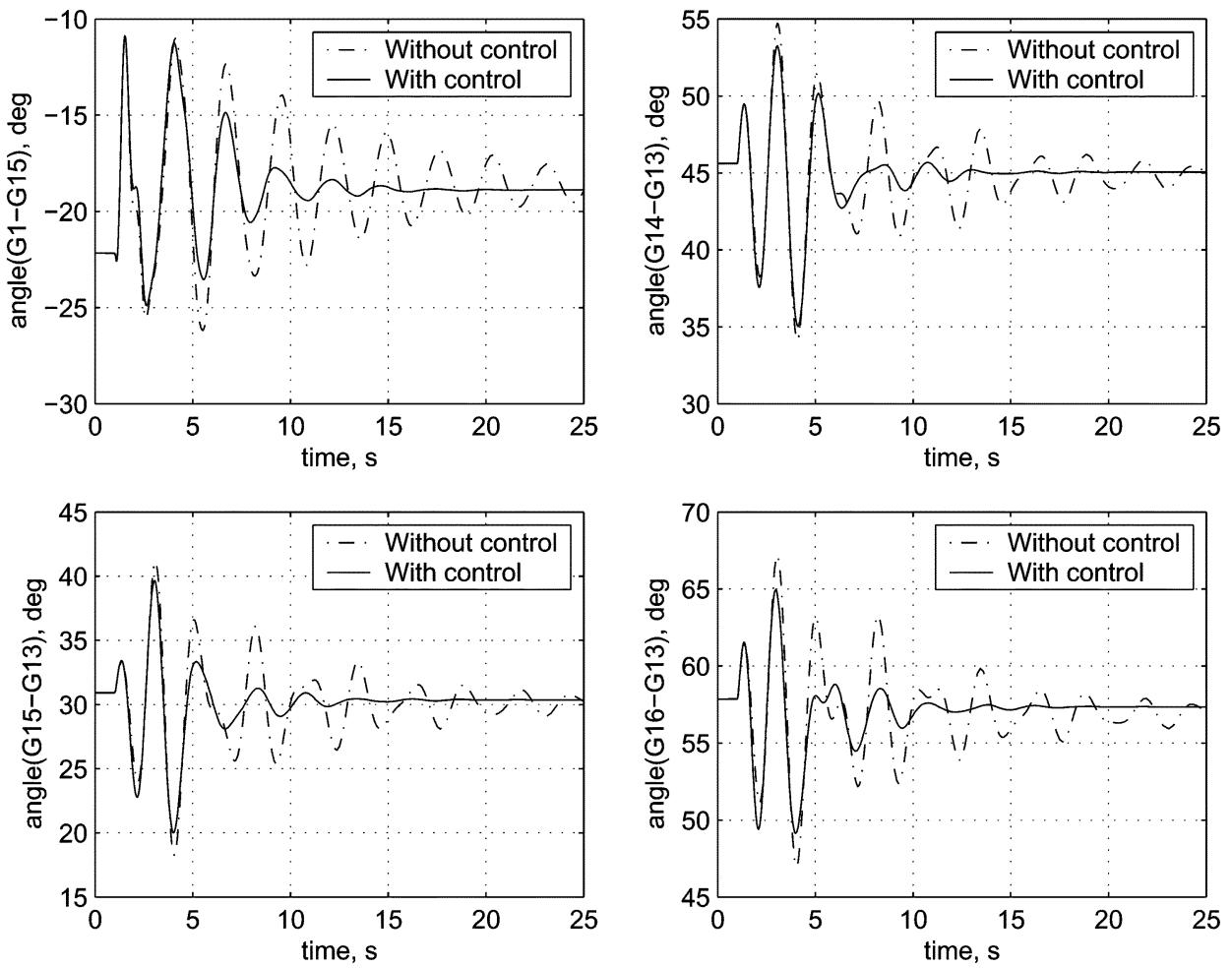

Fig. 8. Machine angles time domain simulation (dashed: uncontrolled, solid: controlled).

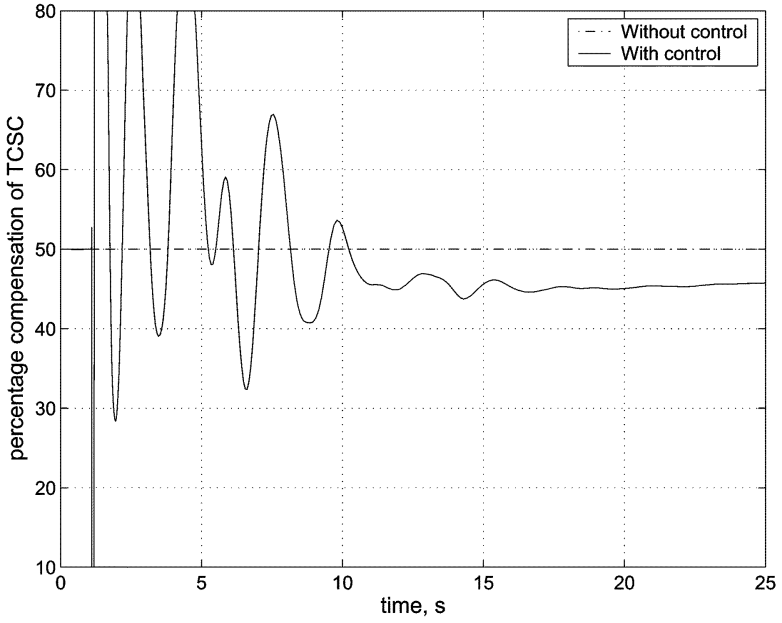

(a) Controller response

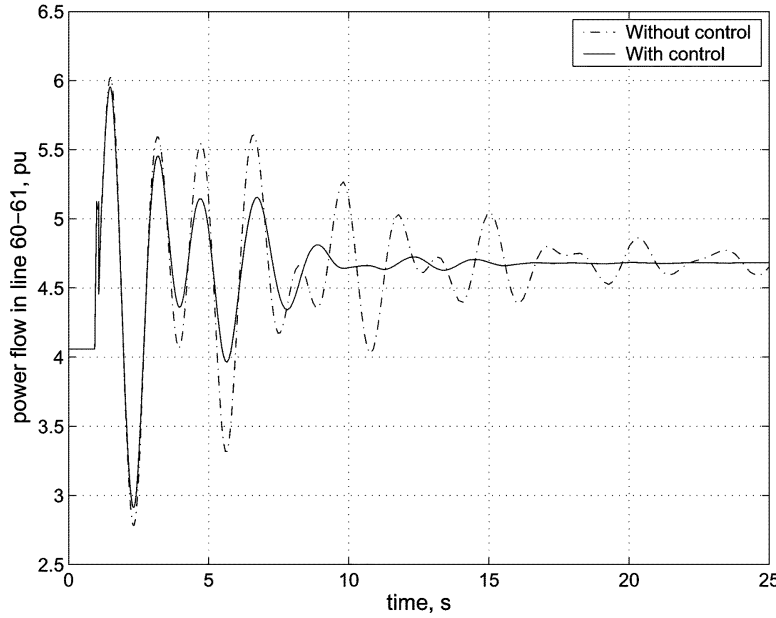

(b) Power flow

Fig. 9. Power flow and controller response time domain simulations (dashed: uncontrolled, solid: controlled).

G13. "Uncontrolled" system characterizes the absence of supplementary damping, while the primary control loop for the TCSC device continues to sustain the steady-state power-flow specifications. It is demonstrated that the inter-area oscillations are successfully damped-out soon after $10 \mathrm{~s}$ using control action (10-15 s is the allowed range). Fig. 9 illustrates the response of the TCSC relative to the power-flow in tie-line between buses \#60-\#61. Initially the control response is quite oscillatory (though within the allowable limits for a TCSC device) owing to the nature of the line-outage, while succeeding to recover soon after. The power flow oscillations are settled soon after $10 \mathrm{~s}$ as expected.

\section{CONCLUSION}

This brief presented a robust LQG/LTR design formulation for improving the damping of power system inter-area oscillations of an equivalent large power system (138th order) using a practical controller structure (7th order) via a TCSC (FACTS) device. The proposed technique of a targeted minimum-phase square system augmentation provided a framework for LTR where the designed system sustains good robustness properties over the required frequency range and despite the variety of uncertainty/operating conditions in the full nonlinear power system model. All required oscillatory modes of interest where 
sufficiently damped over the range of operating conditions, demonstrated via eigenvalue analysis and time domain simulation results.

\section{ACKNOWLEDGMENT}

The authors would like to thank Dr. B.-C. Pal for his valuable comments regarding the power system and FACTS modelling and also R. Majumder for assisting in the controller assessment procedure. They would also like to thank the anonymous reviewers for their helpful criticisms and suggestions for improving the earlier version of this brief.

\section{REFERENCES}

[1] J. Paserba, "Analysis and control of power system oscillation," CIGRE, Special Publication 38.01.07, Tech. Brochure 111, 1996.

[2] P. Korba, M. Larsson, and C. Rehtanz, "Detection of oscillations in power systems using Kalman filtering techniques," in Proc. IEEE Conf. Contr. Appl., 2003, pp. 183-188.

[3] P. Kundur, Power System Stability and Control. New York: McGrawHill, 1994.

[4] H. Werner, P. Korba, and T. Yang, "Robust tuning of power system stabilizers using LMI-techniques," IEEE Trans. Contr. Syst. Technol., vol. 11, no. 1, pp. 147-152, Jan. 2003.

[5] N. Hingorani and L. Gyugyi, Understanding FACTS. Piscataway, NJ: IEEE Press, 2000.

[6] M. Farsangi, Y. Song, W. Fang, and X. Wang, "Robust facts control design using h-infinity loop-shaping method," IEE Proc. Generation Transmission Distrib., vol. 149, no. 3, pp. 352-357, May 2002.

[7] M. Klein, L. Le, G. Rogers, S. Farrokpay, and N. Balu, " $\mathrm{H}_{\infty}$ damping controller design in large power system," IEEE Trans. Power Syst., vol. 10, no. 1, pp. 158-166, Feb. 1995.

[8] B. Pal, A. Coonick, and B. Cory, "Robust damping of interarea oscillations in power systems with superconducting magnetic energy storage devices," IEE Proc. Generation Transmission Distrib., vol. 146, no. 6, pp. 133-639, Nov. 1999.

[9] B. Pal, B. Chaudhuri, A. C. Zolotas, I. M. Jaimoukha, and T. Green, "Mixed-sensitivity approach to $\mathrm{H}_{\infty}$ control of power system oscillations employing multiple facts devices," IEEE Trans. Power Syst., vol. 18, no. 3, pp. 1149-1156, Aug. 2003.

[10] B. Pal, B. Chaudhuri, A. C. Zolotas, and I. M. Jaimoukha, "Simultaneous stabilisation approach for power system damping control design through tcpar employing global signals," Proc. IEE Generation, Transmission Distrib., vol. 151, no. 1, pp. 43-50, Jan. 2004.

[11] J. Smith, F. Fatehi, and D. Pierre, "Closed-loop identification and tuning for damping of interarea modes," in Proc. 33rd IEEE Conf. Dec. Contr., 1994, pp. 4055-4060.

[12] F. Fatehi, J. Smith, and D. Pierre, "Robust power system controller design based on measured models," IEEE Trans. Power Syst., vol. 11, no. 2, pp. 774-780, May 1996.
[13] G. Radman, "Design of power system stabilizer based on LQG/LTR formulations," in Proc. Ind. Appl. Soc. Ann. Meeting/Conf. Record 1992 IEEE, pp. 1787-1792.

[14] K. M. Son and J. K. Park, "On the robust LQG control of TCSC for damping power system oscillations," IEEE Trans. Power Syst., vol. 15, no. 4, pp. 1306-1312, 2000.

[15] B. Chaudhuri and B. Pal, "Robust damping of multiple swing modes employing global stabilizing signals with a TCSC," IEEE Trans. Power Syst., vol. 19, no. 1, pp. 499-506, Feb. 2004.

[16] M. G. Safonov and R. Y. Chiang, "A schur method for balanced model reduction," IEEE Trans. Autom. Contr., vol. AC-34, no. 7, pp. 729-733, Jul. 1989.

[17] S. Skogestad and I. Postlethwaite, Multivariable Feedback Control: Analysis and Design. New York: Wiley, 2000.

[18] J. M. Maciejowski, Multivariable Feedback Design. Reading, MA: Addison-Wesley, 1989.

[19] B. Friedland, Control System Design-An introduction to State Space Methods. New York: McGraw-Hill, 1986.

[20] K. Brammer and G. Siffling, Kalman-Bucy Filters. Norwood, MA: Artech House, 1989.

[21] B. D. O. Anderson and J. B. Moore, Optimal Control: Linear Quadratic Methods. Englewood Cliffs, NJ: Prentice-Hall, 1990.

[22] A. C. Zolotas, "Advanced control strategies for tilting trains," $\mathrm{Ph}$. D. dissertation, Dept. Elect. Electr. Eng., Loughborough Univ., Loughborough, U.K., 2002.

[23] J. C. Doyle, "Guaranteed margins for LQG regulators," IEEE Trans. Autom. Contr., vol. AC-23, no. 4, pp. 756-757, Aug. 1978.

[24] J. C. Doyle and G. Stein, "Robustness with observers," IEEE Trans. Autom. Contr., vol. AC-24, no. 4, pp. 607-611, Aug. 1979.

[25] — "Multivariable feedback design: Concepts for a classical/modern synthesis," IEEE Trans. Autom. Contr., vol. AC-26, no. 1, pp. 4-16, Feb. 1979.

[26] G. Stein and M. Athans, "The LQG/LTR procedure for multivariable feedback control design," IEEE Trans. Autom. Contr., vol. AC-32, no. 2, pp. 105-114, Feb. 1987.

[27] — "Loop transfer recovery for nonminimum phase plants," IEEE Trans. Autom. Contr., vol. 35, no. 5, pp. 547-553, May 1990.

[28] P. Dorato, C. Abdallah, and V. Cerone, Linear Quadratic Control: An Introduction. Englewood Cliffs, NJ: Prentice-Hall, 1994.

[29] A. G. J. MacFarlane and N. Karcanias, "Poles and zeros of linear multivariable systems: A survey of the algebraic, geometric and complexvariable theory," Int. J. Contr., vol. 24, no. 1, pp. 33-74, 1976.

[30] K. Zhou, J. Doyle, and K. Glover, Robust and Optimal Control. Englewood Cliffs, NJ: Prentice-Hall, 1996.

[31] A. Emami-Naeini and P. V. Dooren, "Computation of zeros of linear multivariable systems," Automatica, vol. 18, no. 4, pp. 415-430, 1982.

[32] D. McFarlane and K. Glover, Robust Controller Design Using Normalised Coprime Factor Plant Descriptions, Lecture Notes in Control and Information Sciences. New York: Springer-Verlag, 1990, vol. 138.

[33] I. J. Perez-Arriaga et al., "The role of participation factors in reduced order eigenanalysis of large power systems," in Proc. ISCAS, 1988, pp. 923-927.

[34] J. T. Pearson, R. M. Goodall, and I. Pratt, "Control system studies of an active anti-roll bar tilt system for railway vehicles," Proc. Inst. Mech. Eng., vol. 212, no. F1, pp. 43-60, 1998. 